\title{
Minimally invasive right colectomy - from conventional laparoscopic resection to robotic- assisted surgery: a narrative review
}

\author{
Paolo Moroni ${ }^{1}$, Carmen Payá-Llorente ${ }^{2}$, Lelde Lauka ${ }^{1}$, Elisa Reitano ${ }^{1}$, Riccardo Memeo ${ }^{3}$, Paschalis \\ Gavriilidis $^{4}$, Francesco Brunetti ${ }^{1}$, Aleix Martínez-Pérez ${ }^{2}$ \\ 'Department of Digestive and Hepatobiliary surgery, Henri-Mondor Hospital, University Paris Est-Créteil - UPEC, Créteil \\ 94010, France. \\ 2Department of General and Digestive Surgery, Hospital Universitario Doctor Peset, Valencia 46017, Spain . \\ ${ }^{3}$ Department of Emergency and Organ Transplantation, University Aldo Moro of Bari, Bari 70121, Italy . \\ ${ }^{4}$ Department of Hepato-Biliary-Pancreatic and Oesophago-Gastric Surgery, Imperial College Healthcare NHS Trust, \\ Hammersmith Hospital, London W12 OHS, UK.
}

Correspondence to: Dr. Paolo Moroni, Department of Digestive and Hepatobiliary surgery, Henri-Mondor Hospital, University Paris Est-Créteil - UPEC, 51 Avenue du Maréchal de Lattre de Tassigny, Créteil 94010, France. E-mail: dr.pmoroni@gmail.com

How to cite this article: Moroni P, Payá-Llorente C, Lauka L, Reitano E, Memeo R, Gavriilidis P, Brunetti F, Martínez-Pérez A. Minimally invasive right colectomy - from conventional laparoscopic resection to robotic-assisted surgery: a narrative review. Mini-invasive Surg 2019;3:36. http://dx.doi.org/10.20517/2574-1225.2019.34

Received: 8 Sep 2019 First Decision: 24 Oct 2019 Revised: 8 Nov 2019 Accepted: 13 Nov 2019 Published: 12 Dec 2019

Science Editor: Giulio Belli Copy Editor: Jing-Wen Zhang Production Editor: Tian Zhang

\begin{abstract}
Robotic-assisted abdominal surgery was introduced with the aim of overcoming the drawbacks of the conventional laparoscopic approach. The present narrative review focuses on the comparison between laparoscopic and roboticassisted approaches for right colectomy $(R C)$ regarding short- and long-term outcomes, costs, and learning curve. The main technical aspects related to the use of robotic assistance for this specific procedure are further discussed. Minimally invasive RC is considered technically challenging due to the particularities of the right and middle colic vascular anatomy. Robotic RC is not yet widespread due to its high cost and longer operating time. However, its use may result in advantages regarding short-term clinical outcomes, and it facilitates the acquisition of basic surgical skills by speeding up the learning curve of minimally invasive colorectal surgery.
\end{abstract}

Keywords: Minimally-invasive right colectomy, robotic surgery, laparoscopic surgery, colon cancer, anastomosis, learning curve, costs

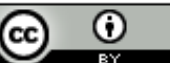

(C) The Author(s) 2019. Open Access This article is licensed under a Creative Commons Attribution 4.0 International License (https://creativecommons.org/licenses/by/4.0/), which permits unrestricted use sharing, adaptation, distribution and reproduction in any medium or format, for any purpose, even commercially, as long as you give appropriate credit to the original author(s) and the source, provide a link to the Creative Commons license, and indicate if changes were made. 


\section{INTRODUCTION}

Colorectal cancer (CRC) is the most common malignant disease of the gastrointestinal tract and the third most common cancer worldwide with over 1,000,000 new diagnoses and 500,000 deaths per year in the United States $^{[1]}$. Approximately $40 \%$ of all CRCs are located in the right colon ${ }^{[2]}$. In recent years, several technical requirements have been established to improve the post-surgery outcomes for colon cancer. The American Joint Committee on Cancer (AJCC) has defined that, for a radical colectomy, a minimum of 12 lymph nodes must be examined to avoid understaging ${ }^{[3,4]}$. Other milestones include the introduction of the principles of complete mesocolic excision $(\mathrm{CME})^{[5]}$ and the introduction and widespread use of minimally-invasive surgery (MIS) ${ }^{[6]}$. For the resection of colon cancer, the use of conventional laparoscopy seems to reduce the length of hospital stay, postoperative pain, and the time until daily activities return to normal, as well as improve cosmetic outcomes when compared to the open approach ${ }^{[7-10]}$. Nevertheless, the adoption of laparoscopic right colectomy (LRC) might not be as widespread as expected ${ }^{[11-15]}$, probably due to the high complexity of the vascular anatomy of the right and transverse colon ${ }^{[16]}$.

For minimally-invasive right colectomy $(\mathrm{RC})$, the debate continues regarding whether the ileo-colonic anastomosis should be performed intra- or extra-corporeally. The majority of the published series on minimally invasive RC have reported an extra-corporeal anastomosis (EA) fashioning ${ }^{[16]}$. Few studies comparing EA with intra-corporeal anastomosis (IA) have been published recently ${ }^{[17]}$. The principles of CME require a meticulous dissection, which increases the technical challenge of LRC. In this scenario, the use of robotic assistance may overcome the limitations of the straight conventional laparoscopic instruments and allow performing a safer CME with central vascular ligation (CVL), especially in obese patients ${ }^{[18]}$. The latest $d a$ Vinci $X i^{\circledast}$ robotic system $(\mathrm{dVXi})$ presents some additional advantages for colorectal procedures when compared with previous versions ( docking, possibility to position the optical system in all of its arms, which are thinner (width 1.7' vs. 2.9'), easier to move, and allow multi-quadrant surgery. The present narrative review aims to describe the main technical aspects of robotic right colectomy (RRC) and compare the learning curve, the short- and longterm outcomes, and the costs between LRC and RRC. A literature search was performed in MEDLINE database (PubMed); articles published in English between 2000 and 2019 using the following terms were screened: "MIS", "RC/colon resection", "robotic surgery", AND "laparoscopic surgery" [Tables 1-3] $]^{[17,19-32]}$.

\section{TECHNICAL ASPECTS OF RRC}

\section{Positioning}

There is no consensus about the position of patient and robot in the operating room. In our center, we put the patient in a supine position tilted on the left side $\left(10^{\circ}-25^{\circ}\right)$ with the arms tight to the body and legs closed. Generally, the table is positioned in Trendelenburg position $\left(5^{\circ}-10^{\circ}\right)^{[33,34]}$ and the robot is placed on the right side of the patient [Figure 1].

\section{Docking}

The pneumoperitoneum is first established. Different options to position the ports have been described, some of which are similar to the conventional laparoscopic approach ${ }^{[35,36]}$. Advances in robotic systems allow variations of the port placement. Moreover, dVXi arms are thinner and have more flexibility, thus decreasing the risk of external collisions when compared to previous robot versions.

\section{Diagonal or oblique port placement}

Four trocars are positioned drawing an oblique line from $4 \mathrm{~cm}$ above the pubic symphysis (Port 1) to the left mid-clavicular line crossing over the left sub-costal margin (Port 4), separated by $7.5 \mathrm{~cm}$. One assistant port can be placed at the level of the umbilicus on the middle clavicular line [Figure 2, red points] ${ }^{[37]}$. 

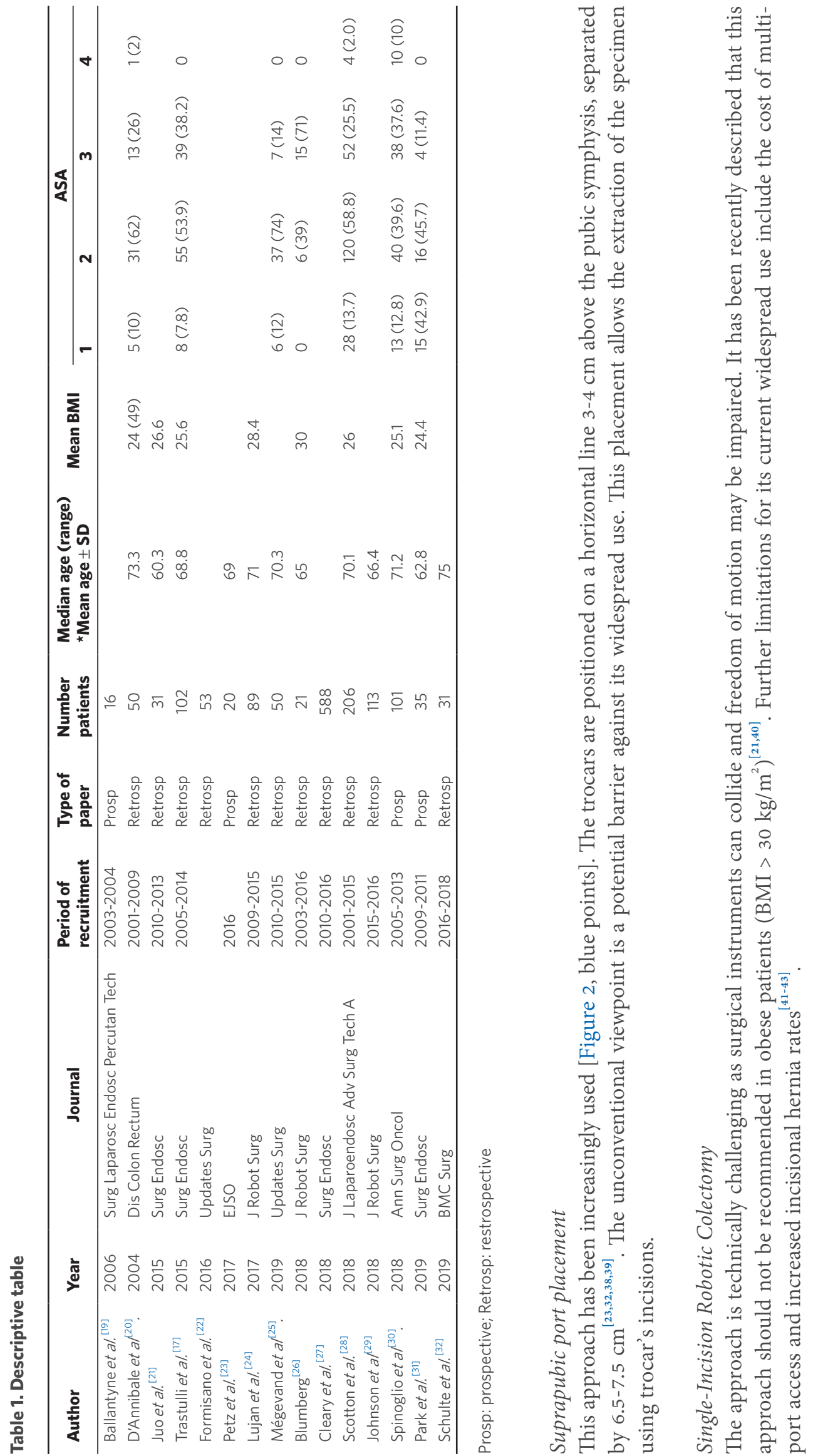

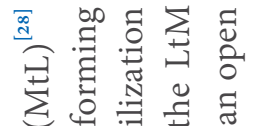

矛

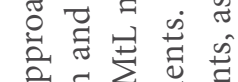

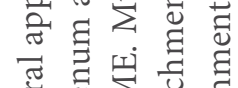

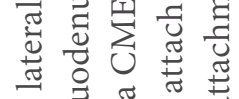

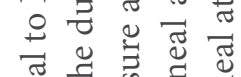

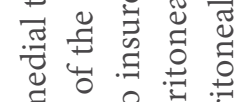

घี

कo

:

范萧

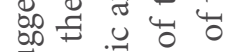

की

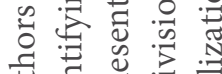

泀苛斈

घี

क त 35

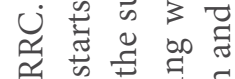

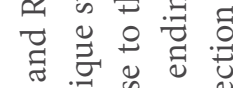

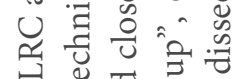

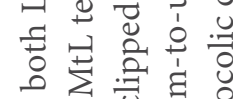

$\exists$ घ

:

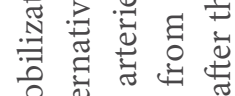

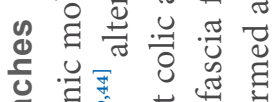

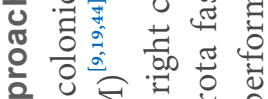

응 它声

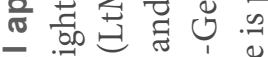

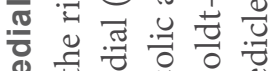

ฮ

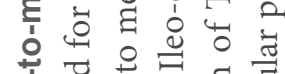

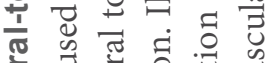

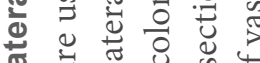

ॠ

म)

ส

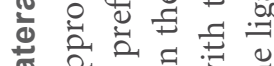

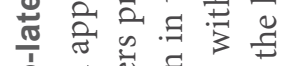

을

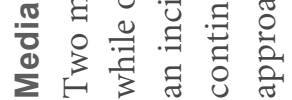



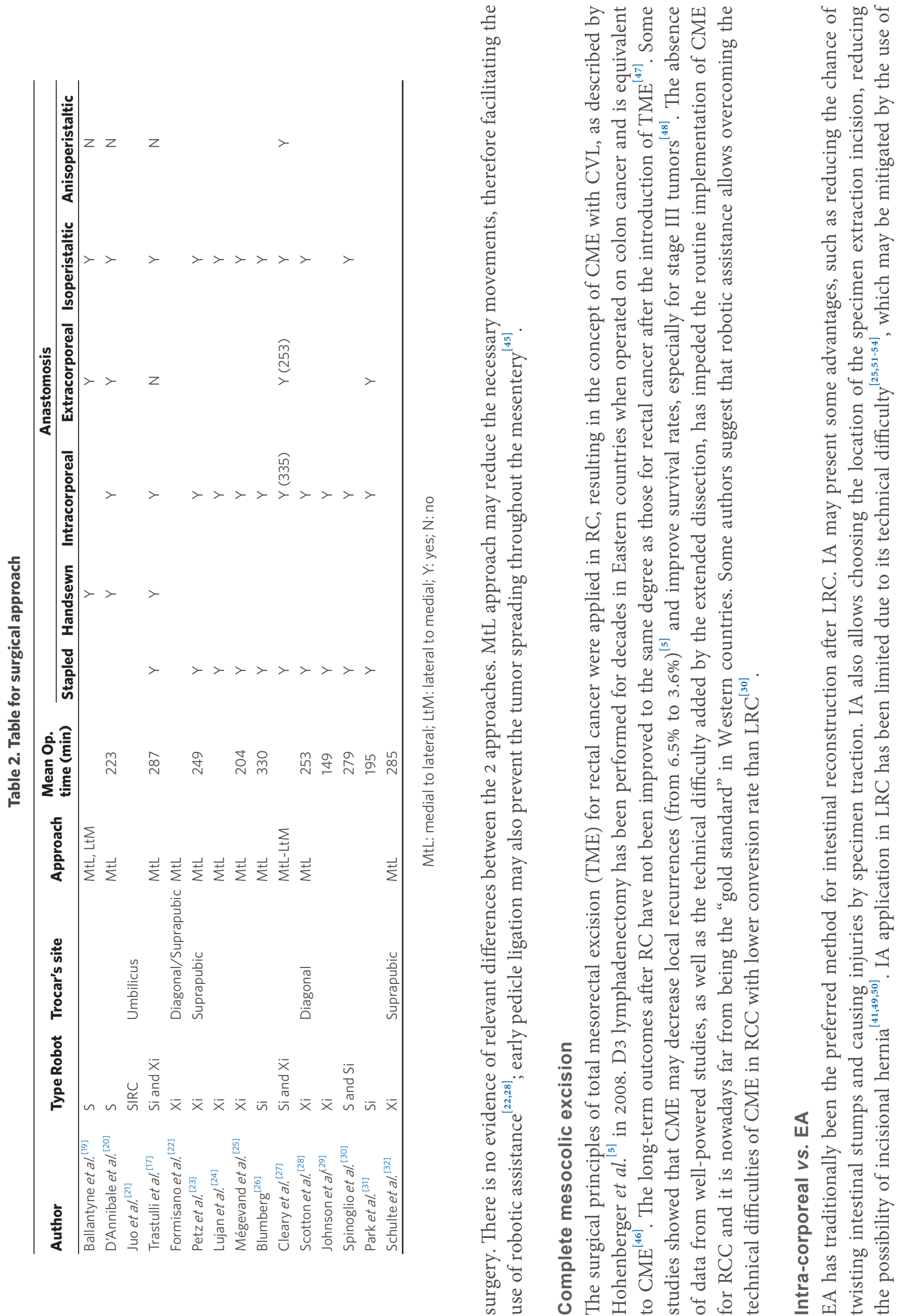
Table 3. Table post-operative

\begin{tabular}{|c|c|c|c|c|c|c|c|c|}
\hline \multirow{2}{*}{ Author } & \multirow{2}{*}{ Conversion (\%) } & \multicolumn{4}{|c|}{ Clavien-Dindo postoperative complications } & \multirow{2}{*}{ - Leak } & \multirow{2}{*}{ Reoperation (\%) } & \multirow{2}{*}{ Readmission (\%) } \\
\hline & & $1(\%)$ & $2(\%)$ & $3(\%)$ & $4(\%)$ & & & \\
\hline Ballantyne et al.. & 0 & & & & & 0 & & \\
\hline D'Annibale et al. ${ }^{[20]}$ & 0 & & & $1(2)$ & & 0 & $1(2)$ & 0 \\
\hline Juo et al. ${ }^{[21]}$ & $1(3.2)$ & & & & & 0 & 0 & 0 \\
\hline Trastulli et al. ${ }^{[17]}$ & $4(3.9)$ & & & & & $3(2.9)$ & $7(6.8)$ & 0 \\
\hline Formisano et al. ${ }^{[22]}$ & $1(1.8)$ & & & & & 0 & 0 & 0 \\
\hline Petz et al. ${ }^{[23]}$ & 0 & 0 & 0 & $2(10)$ & 0 & 0 & 0 & 0 \\
\hline Lujan et al. ${ }^{[24]}$ & $2(2.3)$ & 19 (21.3) & $6(6.7)$ & $1(1.1)$ & 0 & $1(1.1)$ & $1(1.1)$ & $2(2.2)$ \\
\hline Mégevand et al. ${ }^{[25]}$ & 0 & & & & & $2(4)$ & & \\
\hline Blumberg $^{[26]}$ & 0 & & & & & & & \\
\hline \multicolumn{9}{|l|}{ Cleary et al. ${ }^{[27]}$} \\
\hline Scotton et al. ${ }^{[28]}$ & $5(2.4)$ & & & & & $1(0.4)$ & $6(2.9)$ & \\
\hline Johnson et $a{ }^{[29]}$ & 0 & & & & & & 0 & 0 \\
\hline Spinoglio et al. ${ }^{[30]}$ & 0 & & $2(2)$ & & & $1(0.9)$ & $2(2)$ & \\
\hline Park et al. ${ }^{[31]}$ & 0 & & & $1(2.8)$ & & $1(2.8)$ & $1(2.8)$ & 0 \\
\hline Schulte et $\left.a\right|^{[32]}$ & 0 & 9 (29) & $2(6.4)$ & 0 & 0 & 0 & & \\
\hline
\end{tabular}

robotic assistance ${ }^{[5,56]}$. EA may require an extensive mobilization of the transverse colon for reaching the specimen extraction incision ${ }^{[54,57]}$. Two recent meta-analyses in LRC have shown shorter time for first defecation, and oral liquid diet, and decreased length of hospital stay in the IA group ${ }^{[58,59]}$. Van Oostendorp et al ${ }^{[59]}$ also showed a reduction of the short-term postoperative morbidity and surgicalsite infection rate in the IA group. No differences were found regarding the other short-term clinical and histopathological variables evaluated ${ }^{[59]}$. Technical advantages of robotic surgery permit performing an IA more easily. Mégevand et al. ${ }^{[25]}$ reported a series of 100 cases comparing RRC and LRC with IA, and they observed faster intestinal recovery and fewer conversions in the RRC group. Solaini et al. ${ }^{[60]}$, in a subgroup meta-analysis comparing only EA, found no significant differences between RRC and LRC. To date, no randomized controlled trial has been reported comparing RRC and LRC with the same type of anastomosis. Further studies are therefore needed before drawing any conclusion regarding the potential benefits of both IA and robotic assistance in decreasing the odds of anastomotic leak or improving intestinal recovery after RC.

\section{THREE-DIMENSIONAL VERSUS TWO-DIMENSIONAL VIEW IN LRC}

Since the first steps of minimally-invasive surgical procedures, technological research continues to improve its outcomes. In the field of surgical view, a notorious revolution is expected and it is still ongoing. The new laparoscopic platforms together with the new generation of optics allow exceeding the limits of the two-dimensional (2D) view. Abdelrahman et al. ${ }^{[6]}$ reported that three-dimensional (3D) optics with ultrahigh definition $4 \mathrm{k}$ allow a faster learning curve. This experimental evidence was confirmed by Currò et al. ${ }^{[62]}$, who concluded that the $3 \mathrm{D}$ vision improves the depth of perception, which is especially useful in performing an IA, and it also produces less physical strain to the surgeon. However, further studies are needed before drawing any definitive conclusions regarding the potential benefits of $3 \mathrm{D}$ (with or without $4 \mathrm{k}$ ) versus conventional $2 \mathrm{D}$. To date, the choice between $3 \mathrm{D}$ and $2 \mathrm{D}$ systems relies only on the surgeon's preferences and the hospital's resources.

\section{LEARNING CURVE OF MINIMALLY-INVASIVE RC}

Robotic surgery, similar to all the minimally-invasive surgical procedures, requires the acquisition of specific abilities and skills. The learning curve is the number of cases required to achieve expertise with minimal procedural time and complications ${ }^{[63,64]}$. LRC requires a high degree of dexterity and technical skills which result in a learning curve of $20-30$ procedures ${ }^{[36,65,66]}$; this number may increase with IA fashioning ${ }^{[59]}$. Operative time for the first cases of robotic surgery is shorter than that in laparoscopy ${ }^{[67]}$. 


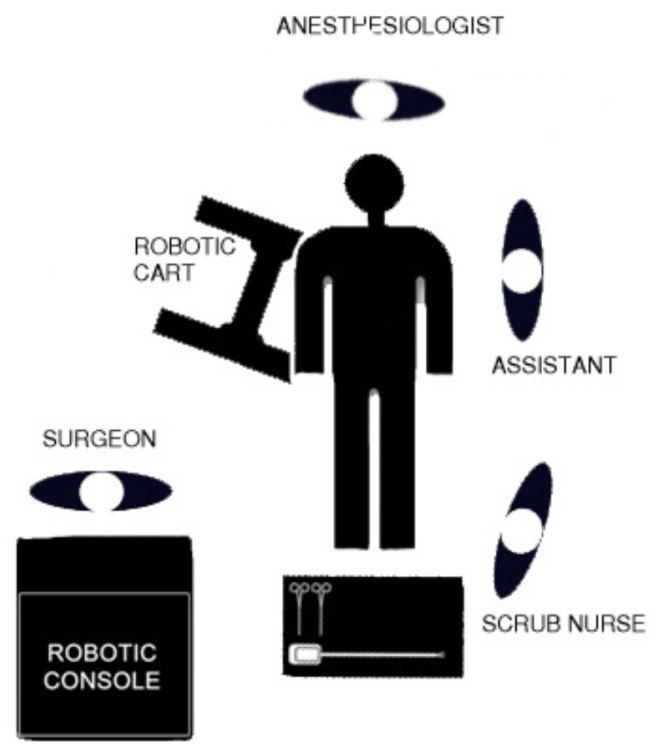

Figure 1. ROBOTIC CONSOLE: robotic platform. SURGEON: first surgeon; ROBOTIC CART: robotic arms; ANESTHESIOLOGIST: anesthesiologist; ASSISTANT: second surgeon; SCRUB NURSE: operative nurse

Additionally, RRC has been proposed as an ideal procedure for the surgeon's initial steps with robotics ${ }^{[68]}$. de'Angelis et al. ${ }^{[36]}$ observed that RRC with EA was associated with a faster learning curve than LRC with EA. Only 16 procedures in the RRC group were needed to significantly reduce operative time versus 25 surgeries in the LLC group. This may be explained by the fact that robotic surgery improves the surgeon's dexterity and depth of perception. Parisi et al. ${ }^{[69]}$ concluded that the learning curve for RRC is around 44 procedures. This long curve was necessary to significantly reduce operative time and conversion to open surgery rate, as well as to significantly increase the number of harvested lymph nodes. Performing RRC can be justified in different situations depending on the type of surgical unit, for example as a training procedure for robotic colorectal surgery for young surgeons in centers that are already skilled at performing RRC. Moreover, centers aiming to incorporate complex robotic procedures could start with $\mathrm{RRC}$ as one of the first of them.

\section{SHORT- AND LONG-TERM OUTCOMES}

Several studies have demonstrated the safety and efficacy of RRC for both short- and long-term outcomes $^{[31,60,70,71]}$. Only one randomized controlled trial found no differences in lengths of hospital stay and the surgical complications rate between RRC and LRC groups ${ }^{[72]}$. The latest meta-analysis published by $\mathrm{Ma}$ et $a{ }^{\left[{ }^{[73]}\right.}$ in 2019 concluded that RRC has a longer operation time, lower estimated blood loss, shorter hospital stay, and lower postoperative complication rate than LRC. Solaini et al. ${ }^{[60]}$ reported that conversion to open surgery was more common during LRC, with no significant differences in mortality and postoperative complication rate. Lim et al. ${ }^{[70]}$ concluded that the time for diet, first flatus, and first defecation, and the length of hospital stay were significantly decreased for RRC. Similarly, Rondelli et al. ${ }^{[74]}$ showed that the time for the first flatus was significantly shorter in RRC. Such differences in recovery may also be related to the less traumatic intra-peritoneal approach provided by the use of IA, rather than purely by the use of robotic assistance. When combined, they can provide a quicker bowel recovery with less need of analgesics ${ }^{[17,75]}$ and fewer post-operative complications ${ }^{[24,74,76-78]}$ Tables 4 and 5$]^{[17,24,30,54,72,76-79]}$.

In a recent retrospective study with 101 patients receiving RRC with CME from 2005 to 2015, Spinoglio et al. ${ }^{[30]}$ showed that it is possible to perform routine RRC with CME and IA safely, with comparable long-term oncologic outcomes to laparoscopic techniques [five-year overall survival (OS) of $77 \%$ and disease-free survival (DFS) of $85 \%$ ]. They also showed a non-significant improvement in DFS for AJCC/UICC stage 


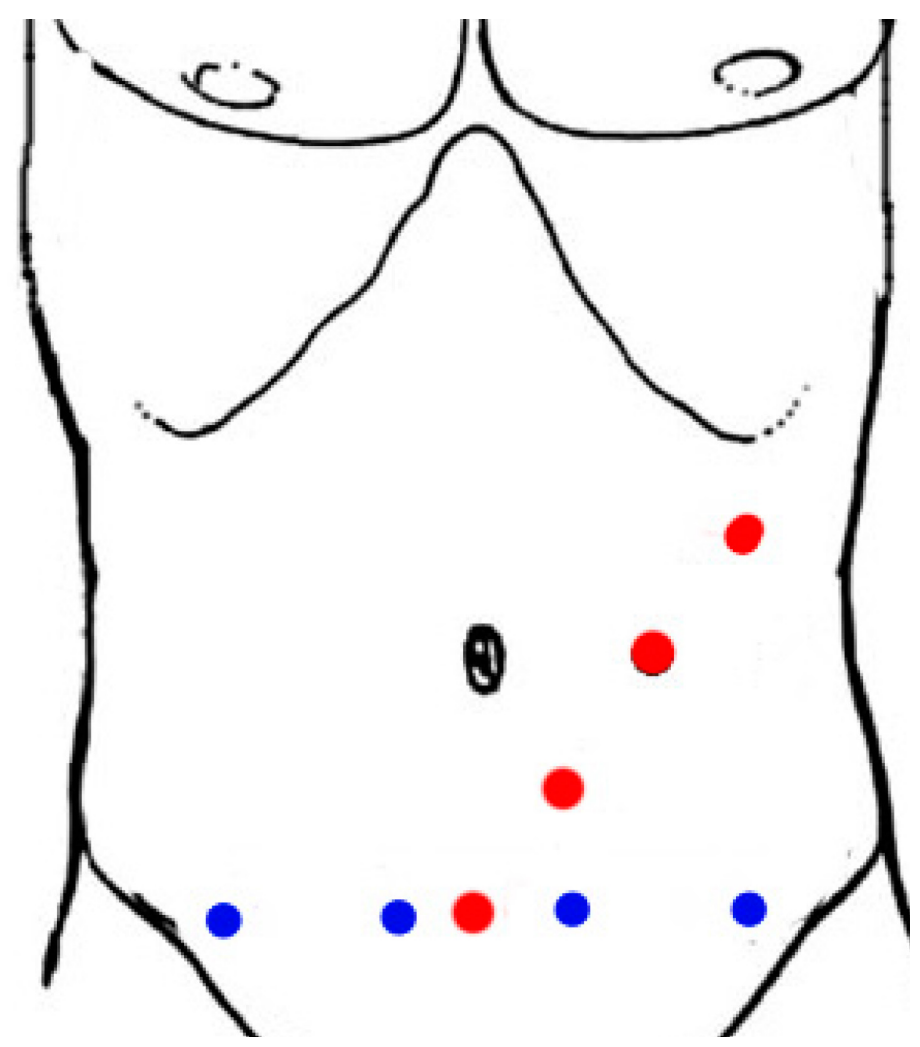

Figure 2. Robot trocar's positions. Red points: diagonal approach; blue points: suprapublic approach

III patients undergoing RRC. Park et al. ${ }^{[31]}$ randomized 71 patients and compared robotic and LRC, and they observed that the long-term outcomes were similar between RRC and LRC with no statistically significant differences at three- and five-year DFS and OS. These findings are consistently reproduced in the contemporary literature ${ }^{[80]}[\text { Table } 6]^{[20,30,72,80,81]}$.

\section{costs}

Cost evaluation in robotic colorectal surgery is crucial to implementing and maintaining the new technology. Nowadays, increased costs are the most important drawback of robotic-assisted surgery and could imply a non-neglectable burden on healthcare systems. Direct costs can be divided into fixed and variable types. The fixed costs include the acquisition of the robotic system, ranging \$0.6-2.5 million, and the costs of further maintenance. The variable costs depends on the consumable instruments, operating room charges, and professional fees. There is a consensus that RRC is more expensive than $\operatorname{LRC}^{[36,60,74,82,83]}$. Park et al ${ }^{[72]}$ determined that the mean direct patient payment for a robotic colectomy was about US $\$ 3600$ more expensive than for a laparoscopic procedure. Cleary et al. ${ }^{[27]}$ reported lower rates of conversion in RRC than in LRC; they also found that RRC was more expensive than LRC, but, when converted patients were included, the difference in cost between RRC and LRC decreased substantially. The total length of hospital stay has an impact on the costs; some of the recent meta-analyses showed that RRC is associated with shorter hospital stay, which may translate to reduced costs ${ }^{[73]}$. It is clearly difficult to assign a monetary value to measured outcomes in cost-effectiveness studies. In a recent study, laparoscopic and robotic colectomy were shown to be more cost-effective than the traditional open resection, laparoscopy being the most cost-effective approach ${ }^{[84]}$. Decreasing costs of robotic platforms and devices is mandatory for its future widespread adoption. Under careful assessment of indications for the different robotic system applications, the advantages of robotic assistance, such as higher degrees of rotation, articulation, and $3 \mathrm{D}$ imaging, can outweigh the existing drawbacks provided by the higher costs. The expected arrival of competitive industry players could dramatically change this situation soon. 

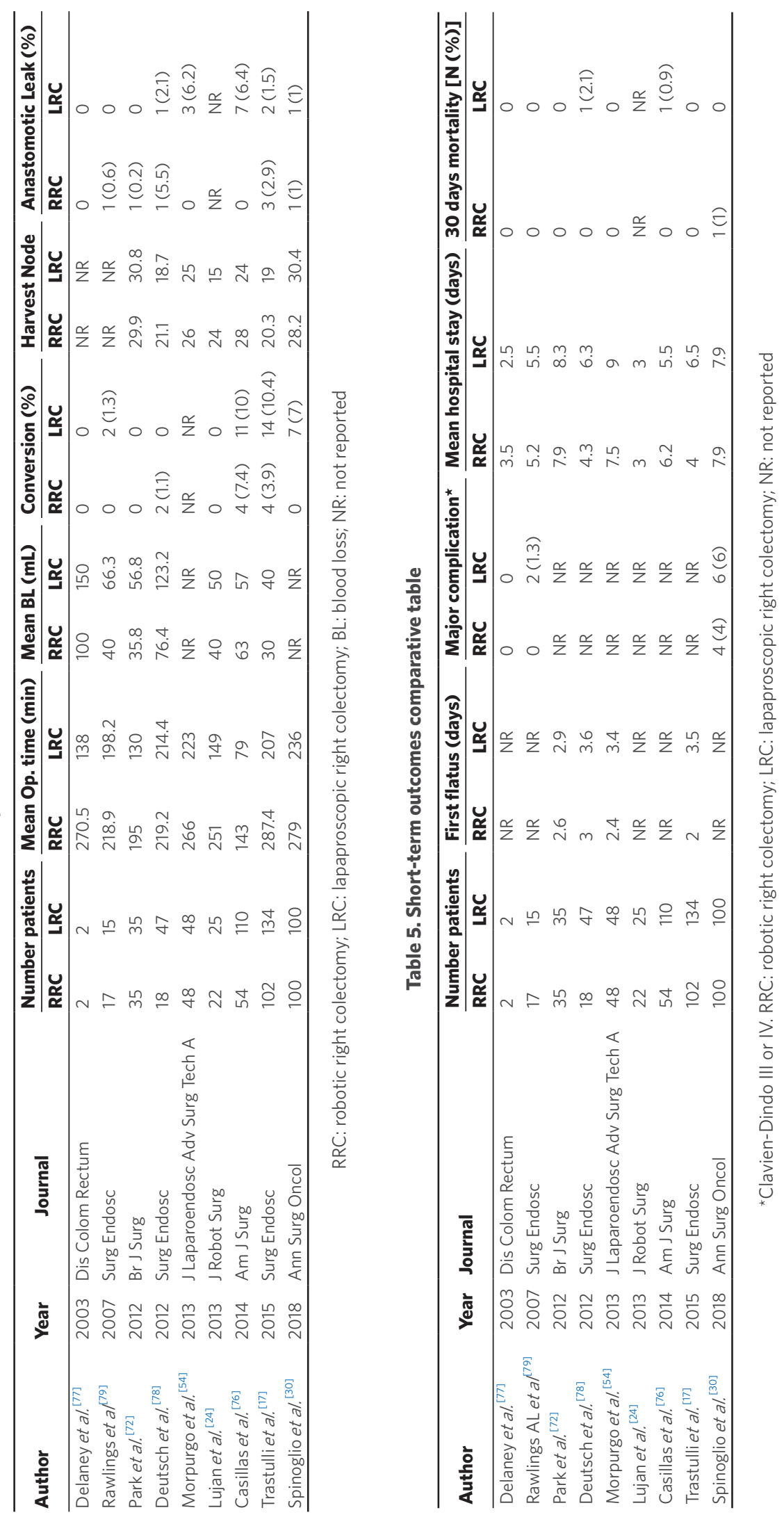

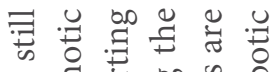
४

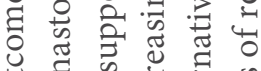
范 원

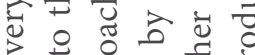
记 to

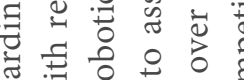
落 过

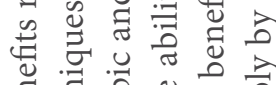

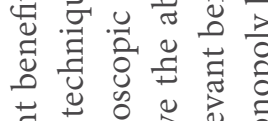

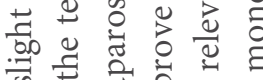

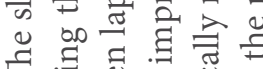

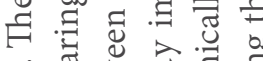

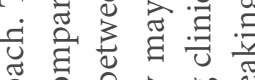
웅 oे तิ प च क के

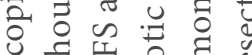
प्र क्ष

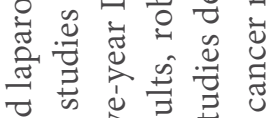

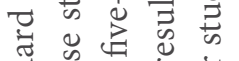

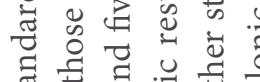
墕焉品 s Ð 递出 : 品

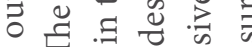
节离节

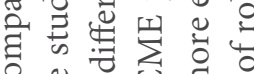

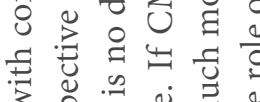
उे

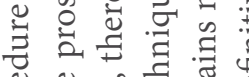
पु

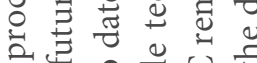

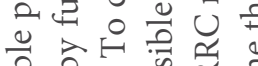
家焉

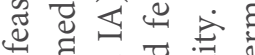

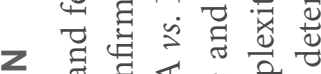

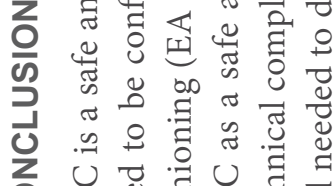

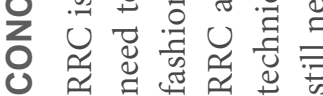



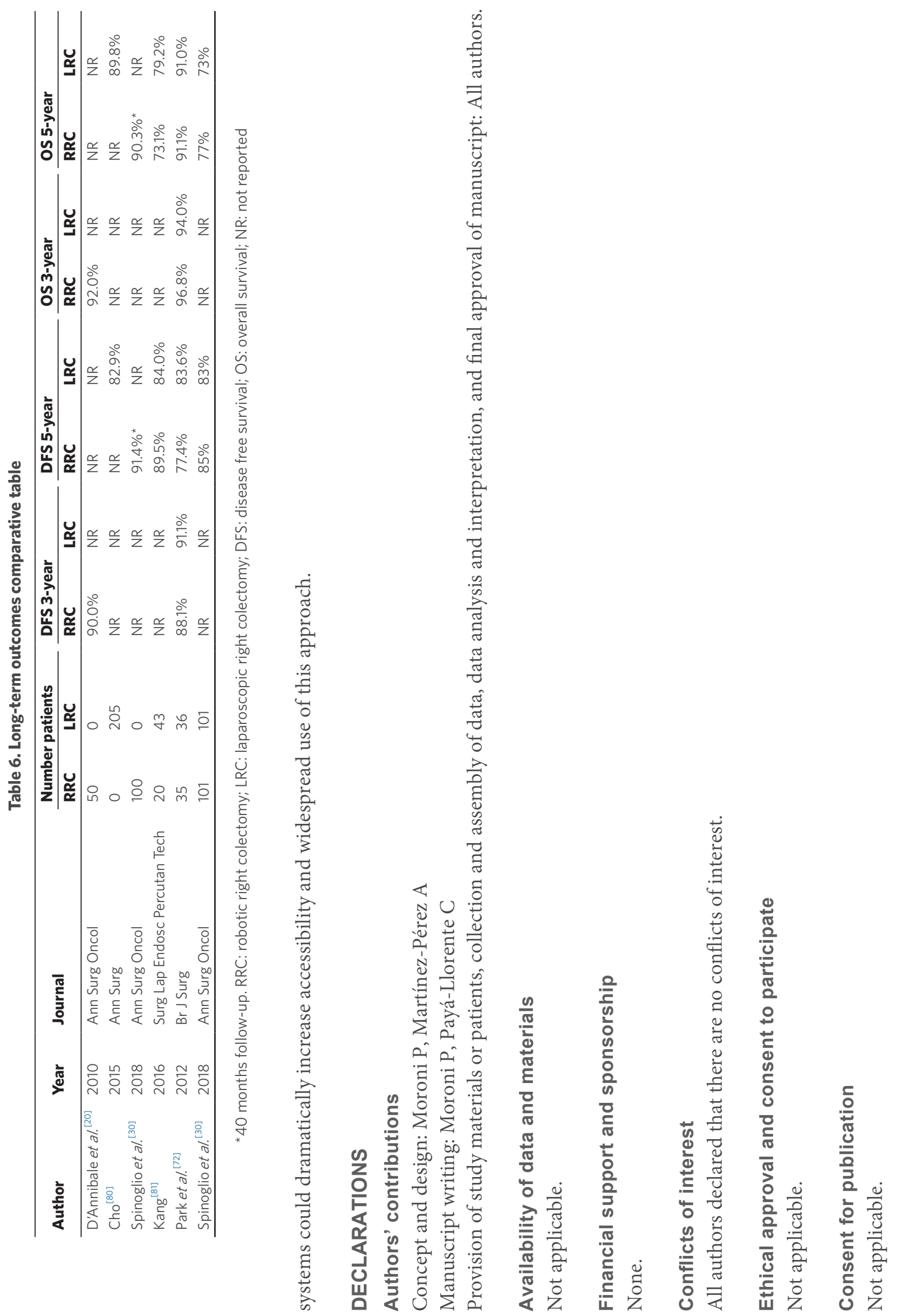


\section{Copyright}

(c) The Author(s) 2019.

\section{REFERENCES}

1. Siegel RL, Miller KD, Fedewa SA, Ahnen DJ, Meester RGS, et al. Colorectal cancer statistics, 2017. CA Cancer J Clin 2017;67:177-93.

2. Ulanja MB, Rishi M, Beutler BD, Sharma M, Patterson DR, et al. Colon cancer sidedness, presentation, and survival at different stages. J Oncol 2019;2019:4315032.

3. Compton C, Fenoglio-Preiser CM, Pettigrew N, Fielding LP. American joint committee on cancer prognostic factors consensus conference: colorectal working group. Cancer 2000;88:1739-57.

4. Yarbro JW, Page DL, Fielding LP, Partridge EE, Murphy GP. American joint committee on cancer prognostic factors consensus conference. Cancer 1999;86:2436-46.

5. Hohenberger W, Weber K, Matzel K, Papadopoulos T, Merkel S. Standardized surgery for colonic cancer: complete mesocolic excision and central ligation - technical notes and outcome. Colorectal Dis 2009;11:354-64; discussion 64-5.

6. Schwenk W, Haase O, Neudecker J, Muller JM. Short term benefits for laparoscopic colorectal resection. Cochrane Database Syst Rev 2005:Cd003145.

7. Green BL, Marshall HC, Collinson F, Quirke P, Guillou P, et al. Long-term follow-up of the Medical Research Council CLASICC trial of conventional versus laparoscopically assisted resection in colorectal cancer. Br J Surg 2013;100:75-82.

8. Buunen M, Veldkamp R, Hop WC, Kuhry E, Jeekel J, et al. Survival after laparoscopic surgery versus open surgery for colon cancer: long-term outcome of a randomised clinical trial. Lancet Oncol 2009;10:44-52.

9. Nelson H, Sargent DJ, Wieand HS, Fleshman J, Anvari M, et al. A comparison of laparoscopically assisted and open colectomy for colon cancer. N Engl J Med 2004;350:2050-9.

10. Veldkamp R, Kuhry E, Hop WC, Jeekel J, Kazemier G, et al. Laparoscopic surgery versus open surgery for colon cancer: short-term outcomes of a randomised trial. Lancet Oncol 2005;6:477-84.

11. Kwon S, Billingham R, Farrokhi E, Florence M, Herzig D, et al. Adoption of laparoscopy for elective colorectal resection: a report from the surgical care and outcomes assessment program. J Am Coll Surg 2012;214:909-18.e1.

12. Delaney CP, Chang E, Senagore AJ, Broder M. Clinical outcomes and resource utilization associated with laparoscopic and open colectomy using a large national database. Ann Surg 2008;247:819-24.

13. Simorov A, Shaligram A, Shostrom V, Boilesen E, Thompson J, et al. Laparoscopic colon resection trends in utilization and rate of conversion to open procedure: a national database review of academic medical centers. Ann Surg 2012;256:462-8.

14. Klugsberger B, Haas D, Oppelt P, Neuner L, Shamiyeh A. Current state of laparoscopic colonic surgery in Austria: a national survey. J Laparoendosc Adv Surg Tech A 2015;25:976-81.

15. Schootman M, Hendren S, Ratnapradipa K, Stringer L, Davidson NO. Adoption of robotic technology for treating colorectal cancer. Dis Colon Rectum 2016;59:1011-8.

16. Bailey MB, Davenport DL, Vargas HD, Evers BM, McKenzie SP. Longer operative time: deterioration of clinical outcomes of laparoscopic colectomy versus open colectomy. Dis Colon Rectum 2014;57:616-22.

17. Trastulli S, Coratti A, Guarino S, Piagnerelli R, Annecchiarico M, et al. Robotic right colectomy with intracorporeal anastomosis compared with laparoscopic right colectomy with extracorporeal and intracorporeal anastomosis: a retrospective multicentre study. Surg Endose 2015;29:1512-21.

18. Cardinali L, Belfiori G, Ghiselli R, Ortenzi M, Guerrieri M. Robotic versus laparoscopic right colectomy for cancer: short-term outcomes and influence of body mass index on conversion rate. Minerva Chir 2016;71:217-22.

19. Ballantyne GH, Ewing D, Pigazzi A, Wasielewski A. Telerobotic-assisted laparoscopic right hemicolectomy: Lateral to medial or medial to lateral dissection? Surg Laparosc Endosc Percutaneous Tech 2006;16:406-10.

20. D'Annibale A, Morpurgo E, Fiscon V, Trevisan P, Sovernigo G, et al. Robotic and laparoscopic surgery for treatment of colorectal diseases. Dis Colon Rectum 2004;47:2162-8.

21. Juo YY, Agarwal S, Luka S, Satey S, Obias V. Single-incision robotic colectomy (SIRC) case series: initial experience at a single center. Surg Endosc 2015;29:1976-81.

22. Formisano G, Misitano P, Giuliani G, Calamati G, Salvischiani L, et al. Laparoscopic versus robotic right colectomy: technique and outcomes. Updates Surg 2016;68:63-9.

23. Petz W, Ribero D, Bertani E, Borin S, Formisano G, et al. Suprapubic approach for robotic complete mesocolic excision in right colectomy: oncologic safety and short-term outcomes of an original technique. Eur J Surg Oncol 2017;43:2060-6.

24. Lujan HJ, Maciel VH, Romero R, Plasencia G. Laparoscopic versus robotic right colectomy: a single surgeon's experience. J Robot Surg 2013;7:95-102.

25. Mégevand JL, Amboldi M, Lillo E, Lenisa L, Ganio E, et al. Right colectomy: consecutive 100 patients treated with laparoscopic and robotic technique for malignancy. Cumulative experience in a single centre. Updates Surg 2019;71:151-6.

26. Blumberg D. Robotic colectomy with intracorporeal anastomosis is feasible with no operative conversions during the learning curve for an experienced laparoscopic surgeon developing a robotics program. J Robot Surg 2019;13:545-55.

27. Cleary RK, Mullard AJ, Ferraro J, Regenbogen SE. The cost of conversion in robotic and laparoscopic colorectal surgery. Surg Endosc 2018;32:1515-24.

28. Scotton G, Contardo T, Zerbinati A, Tosato SM, Orsini C, et al. From laparoscopic right colectomy with extracorporeal anastomosis to robot-assisted intracorporeal anastomosis to totally robotic right colectomy for cancer: the evolution of robotic multiquadrant abdominal surgery. J Laparoendosc Adv Surg Tech A 2018;28:1216-22.

29. Johnson CS, Kassir A, Marx DS, Soliman MK. Performance of da Vinci Stapler during robotic-assisted right colectomy with 
intracorporeal anastomosis. J Robot Surg 2019;13:115-9.

30. Spinoglio G, Bianchi PP, Marano A, Priora F, Lenti LM, et al. Robotic versus laparoscopic right colectomy with complete mesocolic excision for the treatment of colon cancer: perioperative outcomes and 5-year survival in a consecutive series of 202 patients. Ann Surg Oncol 2018;25:3580-6.

31. Park JS, Kang H, Park SY, Kim HJ, Woo IT, et al. Long-term oncologic after robotic versus laparoscopic right colectomy: a prospective randomized study. Surg Endosc 2019;33:2975-81.

32. Schulte Am Esch J, Iosivan SI, Steinfurth F, Mahdi A, Forster C, et al. A standardized suprapubic bottom-to-up approach in robotic right colectomy: technical and oncological advances for complete mesocolic excision (CME). BMC Surg 2019;19:72.

33. Rausa E, Kelly ME, Asti E, Aiolfi A, Bonitta G, et al. Right hemicolectomy: a network meta-analysis comparing open, laparoscopicassisted, total laparoscopic, and robotic approach. Surg Endosc 2019;33:1020-32.

34. Fabozzi M, Cirillo P, Corcione F. Surgical approach to right colon cancer: from open technique to robot. State of art. World J Gastrointest Surg 2016;8:564-73.

35. Huettner F, Rawlings AL, McVay WB, Crawford DL. Robot-assisted laparoscopic colectomy: 70 cases-one surgeon. J Robot Surg 2008:2:227-34.

36. de'Angelis N, Lizzi V, Azoulay D, Brunetti F. Robotic versus laparoscopic right colectomy for colon cancer: analysis of the initial simultaneous learning curve of a surgical fellow. J Laparoendosc Adv Surg Tech A 2016;26:882-92.

37. Nicola de’Angelis, Paolo Moroni, Francesco Brunetti, Aleix Martínez-Pérez. Indocyanine green fluorescence - guided robotic right colectomy with intra-corporeal anastomosis - a video vignette. Colorectal Dis 2019; Epub ahead of print. doi: 10.1111/codi.14820

38. Lee HJ, Choi GS, Park JS, Park SY, Kim HJ, et al. A novel robotic right colectomy for colon cancer via the suprapubic approach using the da Vinci Xi system: initial clinical experience. Ann Surg Treat Res 2018;94:83-7.

39. Yeo SA, Noh GT, Han JH, Cheong C, Stein H, et al. Universal suprapubic approach for complete mesocolic excision and central vascular ligation using the da Vinci Xi ${ }^{\circledR}$ system: from cadaveric models to clinical cases. J Robot Surg 2017;11:399-407.

40. Ostrowitz MB, Eschete D, Zemon H, DeNoto G. Robotic-assisted single-incision right colectomy: early experience. Int J Med Robot 2009;5:465-70.

41. Samia H, Lawrence J, Nobel T, Stein S, Champagne BJ, et al. Extraction site location and incisional hernias after laparoscopic colorectal surgery: should we be avoiding the midline? Am J Surg 2013;205:264-7; discussion 268 .

42. Lee L, Mappin-Kasirer B, Sender Liberman A, Stein B, Charlebois P, et al. High incidence of symptomatic incisional hernia after midline extraction in laparoscopic colon resection. Surg Endosc 2012;26:3180-5.

43. Singh R, Omiccioli A, Hegge S, McKinley C. Does the extraction-site location in laparoscopic colorectal surgery have an impact on incisional hernia rates? Surg Endosc 2008;22:2596-600.

44. Weeks JC, Nelson H, Gelber S, Sargent D, Schroeder G. Short-term quality-of-life outcomes following laparoscopic-assisted colectomy vs. open colectomy for colon cancer: a randomized trial. Jama 2002;287:321-8.

45. Lynch ML, Brand MI. Preoperative evaluation and oncologic principles of colon cancer surgery. Clin Colon Rectal Surg 2005;18:16373.

46. West NP, Kobayashi H, Takahashi K, Perrakis A, Weber K, et al. Understanding optimal colonic cancer surgery: comparison of Japanese D3 resection and European complete mesocolic excision with central vascular ligation. J Clin Oncol 2012;30:1763-9.

47. Heald RJ, Ryall RD. Recurrence and survival after total mesorectal excision for rectal cancer. Lancet 1986;1:1479-82.

48. West NP, Morris EJ, Rotimi O, Cairns A, Finan PJ, et al. Pathology grading of colon cancer surgical resection and its association with survival: a retrospective observational study. Lancet Oncol 2008;9:857-65.

49. Ricci C, Casadei R, Alagna V, Zani E, Taffurelli G, et al. A critical and comprehensive systematic review and meta-analysis of studies comparing intracorporeal and extracorporeal anastomosis in laparoscopic right hemicolectomy. Langenbecks Arch Surg 2017;402:41727.

50. Harr JN, Juo YY, Luka S, Agarwal S, Brody F, et al. Incisional and port-site hernias following robotic colorectal surgery. Surg Endosc 2016;30:3505-10

51. Reitz ACW, Lin E, Rosen SA. A single surgeon's experience transitioning to robotic-assisted right colectomy with intracorporeal anastomosis. Surg Endosc 2018;32:3525-32.

52. Fabozzi M, Allieta R, Brachet Contul R, Grivon M, Millo P, et al. Comparison of short- and medium-term results between laparoscopically assisted and totally laparoscopic right hemicolectomy: a case-control study. Surg Endosc 2010;24:2085-91.

53. Hanna MH, Hwang GS, Phelan MJ, Bui TL, Carmichael JC, et al. Laparoscopic right hemicolectomy: short- and long-term outcomes of intracorporeal versus extracorporeal anastomosis. Surg Endosc 2016;30:3933-42.

54. Morpurgo E, Contardo T, Molaro R, Zerbinati A, Orsini C, et al. Robotic-assisted intracorporeal anastomosis versus extracorporeal anastomosis in laparoscopic right hemicolectomy for cancer: a case control study. J Laparoendosc Adv Surg Tech A 2013;23:414-7.

55. Tam MS, Kaoutzanis C, Mullard AJ, Regenbogen SE, Franz MG, et al. A population-based study comparing laparoscopic and robotic outcomes in colorectal surgery. Surg Endosc 2016;30:455-63.

56. Tou S, Duncan A, Giuratrabocchetta S, Bergamaschi R. Robotic right colectomy with intracorporeal anastomosis - a video vignette Colorectal Dis 2015;17:1030-1

57. Cirocchi R, Trastulli S, Farinella E, Guarino S, Desiderio J, et al. Intracorporeal versus extracorporeal anastomosis during laparoscopic right hemicolectomy - systematic review and meta-analysis. Surg Oncol 2013;22:1-13.

58. Wu Q, Jin C, Hu T, Wei M, Wang Z. Intracorporeal versus extracorporeal anastomosis in laparoscopic right colectomy: a systematic review and meta-analysis. J Laparoendosc Adv Surg Tech A 2017;27:348-57.

59. van Oostendorp S, Elfrink A, Borstlap W, Schoonmade L, Sietses C, et al. Intracorporeal versus extracorporeal anastomosis in right hemicolectomy: a systematic review and meta-analysis. Surg Endosc 2017;31:64-77.

60. Solaini L, Bazzocchi F, Cavaliere D, Avanzolini A, Cucchetti A, et al. Robotic versus laparoscopic right colectomy: an updated 
systematic review and meta-analysis. Surg Endosc 2018;32:1104-10.

61. Abdelrahman M, Belramman A, Salem R, Patel B. Acquiring basic and advanced laparoscopic skills in novices using two-dimensional (2D), three-dimensional (3D) and ultra-high definition (4K) vision systems: a randomized control study. Int J Surg 2018;53:333-8.

62. Currò G, Cogliandolo A, Bartolotta M, Navarra G. Three-dimensional versus two-dimensional laparoscopic right hemicolectomy. J Laparoendosc Adv Surg Tech A 2016;26:213-7.

63. Marusch F, Gastinger I, Schneider C, Scheidbach H, Konradt J, et al. Experience as a factor influencing the indications for laparoscopic colorectal surgery and the results. Surg Endosc 2001;15:116-20.

64. Choi DH, Jeong WK, Lim SW, Chung TS, Park JI, et al. Learning curves for laparoscopic sigmoidectomy used to manage curable sigmoid colon cancer: single-institute, three-surgeon experience. Surg Endosc 2009;23:622-8.

65. Li JC, Hon SS, Ng SS, Lee JF, Yiu RY, et al. The learning curve for laparoscopic colectomy: experience of a surgical fellow in an university colorectal unit. Surg Endosc 2009;23:1603-8.

66. Dincler S, Koller MT, Steurer J, Bachmann LM, Christen D, et al. Multidimensional analysis of learning curves in laparoscopic sigmoid resection: eight-year results. Dis Colon Rectum 2003;46:1371-8; discussion 8-9.

67. Melich G, Hong YK, Kim J, Hur H, Baik SH, et al. Simultaneous development of laparoscopy and robotics provides acceptable perioperative outcomes and shows robotics to have a faster learning curve and to be overall faster in rectal cancer surgery: analysis of novice MIS surgeon learning curves. Surg Endosc 2015;29:558-68.

68. Witkiewicz W, Zawadzki M, Rząca M, Obuszko Z, Czarnecki R, et al. Robot-assisted right colectomy: surgical technique and review of the literature. Wideochir Inne Tech Maloinwazyjne 2013;8:253-7.

69. Parisi A, Scrucca L, Desiderio J, Gemini A, Guarino S, et al. Robotic right hemicolectomy: analysis of 108 consecutive procedures and multidimensional assessment of the learning curve. Surg Oncol 2017;26:28-36.

70. Lim S, Kim JH, Baek SJ, Kim SH, Lee SH. Comparison of perioperative and short-term outcomes between robotic and conventional laparoscopic surgery for colonic cancer: a systematic review and meta-analysis. Ann Surg Treat Res 2016;90:328-39.

71. deSouza AL, Prasad LM, Park JJ, Marecik SJ, Blumetti J, et al. Robotic assistance in right hemicolectomy: is there a role? Dis Colon Rectum 2010;53:1000-6.

72. Park JS, Choi GS, Park SY, Kim HJ, Ryuk JP. Randomized clinical trial of robot-assisted versus standard laparoscopic right colectomy. Br J Surg 2012;99:1219-26.

73. Ma S, Chen Y, Guo T, Yang X, Lu Y, et al. Short-term outcomes of robotic-assisted right colectomy compared with laparoscopic surgery: a systematic review and meta-analysis. Asian J Surg 2019;42:589-98.

74. Rondelli F, Balzarotti R, Villa F, Guerra A, Avenia N, et al. Is robot-assisted laparoscopic right colectomy more effective than the conventional laparoscopic procedure? a meta-analysis of short-term outcomes. Int J Surg 2015;18:75-82.

75. Xu H, Li J, Sun Y, Li Z, Zhen Y, et al. Robotic versus laparoscopic right colectomy: a meta-analysis. World J Surg Oncol 2014;12:274.

76. Casillas MA Jr, Leichtle SW, Wahl WL, Lampman RM, Welch KB, et al. Improved perioperative and short-term outcomes of robotic versus conventional laparoscopic colorectal operations. Am J Surg 2014;208:33-40.

77. Delaney CP, Lynch AC, Senagore AJ, Fazio VW. Comparison of robotically performed and traditional laparoscopic colorectal surgery. Dis Colon Rectum 2003;46:1633-9.

78. Deutsch GB, Sathyanarayana SA, Gunabushanam V, Mishra N, Rubach E, et al. Robotic vs. laparoscopic colorectal surgery: an institutional experience. Surg Endosc 2012;26:956-63.

79. Rawlings AL, Woodland JH, Vegunta RK, Crawford DL. Robotic versus laparoscopic colectomy. Surg Endosc 2007;21:1701-8.

80. Cho MS, Baek SJ, Hur H, Soh Min B, Baik SH, et al. Modified complete mesocolic excision with central vascular ligation for the treatment of right-sided colon cancer: long-term outcomes and prognostic factors. Ann Surg 2015;261:708-15.

81. Davis BR, Yoo AC, Moore M, Gunnarsson C. Robotic-assisted versus laparoscopic colectomy: cost and clinical outcomes. JSLS $2014 ; 18: 211-24$

82. Kang J, Park YA, Baik SH, Sohn SK, Lee KY. A Comparison of Open, Laparoscopic, and Robotic Surgery in the Treatment of Rightsided Colon Cancer. Surg Laparosc Endosc Percutan Tech 2016;26:497-502

83. Dolejs SC, Waters JA, Ceppa EP, Zarzaur BL. Laparoscopic versus robotic colectomy: a national surgical quality improvement project analysis. Surg Endosc 2017;31:2387-96.

84. Simianu VV, Gaertner WB, Kuntz K, Kwaan MR, Lowry AC, et al. Cost-effectiveness evaluation of laparoscopic versus robotic minimally invasive colectomy. Ann Surg 2019; Epub ahead of print doi: 10.1097/SLA.0000000000003196 